\title{
Word Pronunciation Disambiguation using the Web
}

\author{
Eiichiro Sumita ${ }^{1,2}$ \\ ${ }^{1} \mathrm{NiCT}$ \\ ${ }^{2}$ ATR SLC \\ Kyoto 619-0288, JAPAN \\ eiichiro.sumita@atr.jp
}

\author{
Fumiaki Sugaya $^{3}$ \\ ${ }^{3}$ KDDI R\&D Labs \\ Saitama 356-8502, JAPAN \\ fsugaya@kddilabs.jp
}

\begin{abstract}
This paper proposes an automatic method of reading proper names with multiple pronunciations. First, the method obtains Web pages that include both the proper name and its pronunciation. Second, the method feeds them to the learner for classification. The current accuracy is around $90 \%$ for open data.
\end{abstract}

\section{Introduction}

Within text-to-speech programs, it is very important to deal with heteronyms, that is, words that are spelt the same but that have different readings, e.g. "bow" (a ribbon) and "bow" (of a ship). Reportedly, Japanese text-to-speech programs read sentences incorrectly more than 10 percent of the time. This problem is mainly caused by heteronyms and three studies have attempted to solve it (Yarowsky, 1996; Li and Takeuchi, 1997; and Umemura and Shimizu, 2000).

They assumed that the pronunciation of a word corresponded directly to the sense tag or part-ofspeech of that word. In other words, sense tagging and part-of-speech tagging can determine the reading of a word. However, proper names have the same sense tag, for example, "location" for landmarks and the same part-of-speech, the "noun." Clearly then, reading proper names is outside the scope of previous studies. Also, the proper names of locations, people, organizations, and others are dominant sources of heteronyms. Here, we focus on proper names. Our proposal is similar to previous studies in that both use machine learning. However, previous methods used expensive resources, e.g., a corpus in which words are manually tagged according to their pronunciation. Instead, we propose a method that automatically builds a pronunciation-tagged corpus using the Web as a source of training data for word pronunciation disambiguation.

This paper is arranged as follows. Section 2 proposes solutions, and Sections 3 and 4 report experimental results. We offer our discussion in Section 5 and conclusions in Section 6.

\section{The Proposed Methods}

It is crucial to correctly read proper names in opendomain text-to-speech programs, for example, applications that read Web pages or newspaper articles. To the best of our knowledge, no other studies have approached this problem. In this paper, we focus on the Japanese language. In this section, we first explain the Japanese writing system (Sections 2.1), followed by our proposal, the basic method (Section 2.2), and the improved method (Section 2.3).

\subsection{The Japanese writing system}

First, we should briefly explain the modern Japanese writing system. The Japanese language is represented by three scripts:

[i] Kanji, which are characters of Chinese origin;

[ii] Hiragana, a syllabary (reading); and

[iii] Katakana, also a syllabary (reading).

\begin{tabular}{|l|l|}
\multicolumn{1}{l|}{ Script } & \multicolumn{1}{l|}{ Sample } \\
\hline KANJI & 大平 \\
\hline HIRAGANA (reading) & おおだいら \\
\hline KATAKANA (reading) & オオダイラ \\
\hline
\end{tabular}

Table 1 Three writings of a single word 
As exemplified in Table 1, there are three writings for the word “大平." The lower two samples are representations of the same pronunciation of "oo daira."

Listing possible readings can be done by consulting a dictionary (see Section 3.1 for the experiment). Therefore, in this paper, we assume that listing is performed prior to disambiguation.

\subsection{The basic method based on page hits}

The idea is based on the observation that proper names in Kanji often co-occur with their pronunciation in Hiragana (or Katakana) within a single Web page, as shown Figure 1. In the figure, the name “大平" in Kanji is indicated with an oval, and its pronunciation in Katakana, “オオダ イラ,” is high-lighted with the dotted oval.

According to Google, there are 464 pages in which “大平” and “オオダイラ” co-occur.

In this sense, the co-occurrence frequency suggests to us the most common pronunciation.

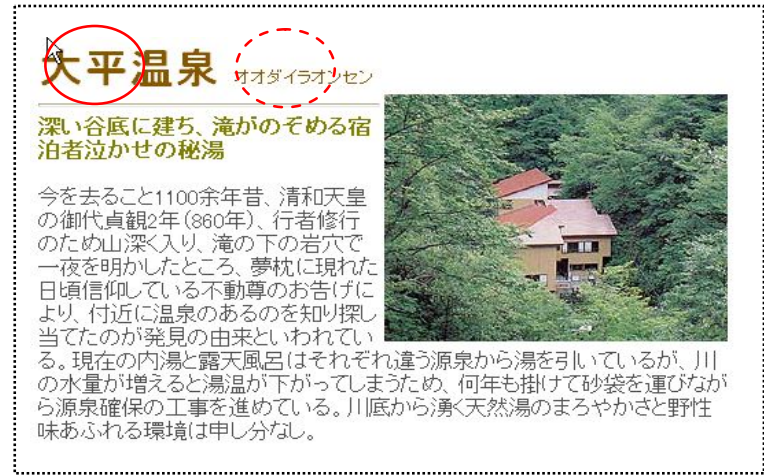

Figure 1 On the Web, words written in Kanji often co-occur with the pronunciation written in Katakana $^{1}$

Our simple proposal to pick up the most frequent pronunciation achieves surprisingly high accuracy for open data, as Section 4 will later show.

\subsection{The improved method using a classifier}

The basic method mentioned above merely selects the most frequent pronunciation and neglects all others. This is not disambiguation at all.

The improved method is similar to standard word-sense disambiguation. The hit pages can pro-

1 http://oyudokoro.mimo.com/area/C/cd/tng/000370/index.html vide us with training data for reading a particular word. We feed the downloaded data into the learner of a classifier. We do not stick to a certain method of machine learning; any state-of-the-art method will work. The features used in classification will be explained in the latter half of this subsection.

\section{Collecting training data from the Web}

Our input is a particular word, $\mathrm{W}$, and the set of its readings, $\left\{\mathrm{R}_{\mathrm{k}} \mid \mathrm{k}=1 \sim \mathrm{K}\right\}$.

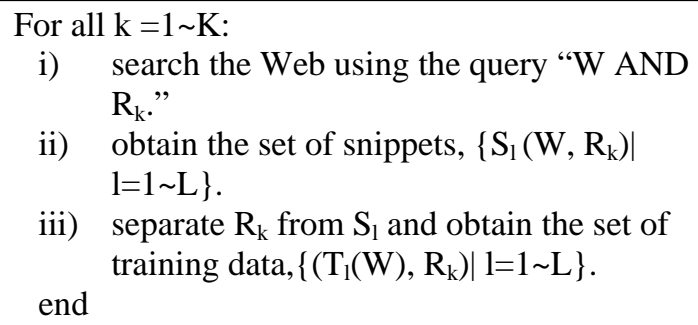

In the experiments for this report, $\mathrm{L}$ is set to 1,000. Thus, for each reading $R_{k}$ of $W$, we have, at most 1,000 training data $\mathrm{T}_{1}(\mathrm{~W})$.

\section{Training the classifier}

From the training data $T_{l}(W)$, we make feature vectors that are fed into the learner of the decision tree with the correct reading $R_{k}$ for the word in question, $\mathrm{W}$.

Here, we write $T_{1}(\mathrm{~W})$ as $\mathrm{W}_{-\mathrm{m}} \mathrm{W}_{-(\mathrm{m}-1)} \ldots \mathrm{W}_{-2} \mathrm{~W}_{-1}$ $\mathrm{W} \mathrm{W}_{1} \mathrm{~W}_{2} \ldots \mathrm{W}_{\mathrm{m}-1} \mathrm{~W}_{\mathrm{m}}$, where $\mathrm{m}$ is from 2 to $\mathrm{M}$, which hereafter is called the window size.

We use two kinds of features:

- The part-of-speech of $\mathrm{W}_{-2} \mathrm{~W}_{-1}$ and $\mathrm{W}_{1} \mathrm{~W}_{2}$

- Keywords within the snippet. In this experiment, keywords are defined as the top $\mathrm{N}$ frequent words, but for $\mathrm{W}$ in the bag consisting of all words in $\left\{\mathrm{T}_{1}(\mathrm{~W})\right\}$.

In this paper, $\mathrm{N}$ is set to 100 . These features ground the pronunciation disambiguation task to the real world through the Web. In other words, they give us knowledge about the problem at hand, i.e., how to read proper names in a real-world context.

\section{Experimental Data}

We conducted the experiments using proper location names. 


\subsection{Ambiguous name lists}

Japan Post openly provides postal address lists associated with pronunciations .

From that list, we extracted 79,861 pairs of proper location names and their pronunciations. As the breakdown of Table 2 shows, 5.7\% of proper location names have multiple pronunciations, while $94.3 \%$ have a single pronunciation. The average ambiguity is 2.26 for ambiguous types. Next, we took into consideration the frequency of each proper name on the Web. Frequency is surrogated by the page count when the query of a word itself is searched for using a search engine. About one quarter of the occurrences were found to be ambiguous.

\begin{tabular}{|c|c|c|}
\hline $\begin{array}{l}\text { Number of } \\
\text { readings }\end{array}$ & type & $\%$ \\
\hline 1 & 70,232 & 94.3 \\
\hline 2 & 3,443 & \multirow{8}{*}{5.7} \\
\hline 3 & 599 & \\
\hline 4 & 150 & \\
\hline 5 & 45 & \\
\hline 6 & 11 & \\
\hline 7 & 4 & \\
\hline 8 & 2 & \\
\hline 11 & 1 & \\
\hline total & 74,487 & 100.0 \\
\hline
\end{tabular}

Table 2 Pronunciation ambiguities in Japanese location names

Our proposal depends on co-occurrences on a Web page. If the pairing of a word $\mathrm{W}$ and its reading $\mathrm{R}$ do not occur on the Web, the proposal will not work. We checked this, and found that there was only one pair missing out of the 79,861 on our list. In this sense, the coverage is almost $100 \%$.

\subsection{Open Data}

We tested the performance of our proposed methods on openly available data.

Open data were obtained from the EDR corpus, which consists of sentences from Japanese newspapers. Every word is tagged with part-of-speech and pronunciation.

We extracted sentences that include location heteronyms, that is, those that contain Kanji that can be found in the above-mentioned list of location heteronyms within the postal address data.
There were 268 occurrences in total. There were 72 types of heteronyms.

\section{Experiment Results}

We conducted two experiments: (1) an open test; and (2) a study on the degree of ambiguity.

\subsection{Open test}

We evaluated our proposals, i.e., the basic method and the improved method with the open data explained in Section 3.1. Both methods achieved a high rate of accuracy.

\section{Basic method performance}

In the basic method, the most common pronunciation on the Web is selected. The frequency is estimated by the page count of the query for the pairing of the word $\mathrm{W}$ and its pronunciation, $\mathrm{R}_{\mathrm{i}}$.

There are two variations based on the Hiragana and Katakana pronunciation scripts. The average accuracy for the open data was $89.2 \%$ for Hiragana and $86.6 \%$ for Katakana (Table 3). These results are very high, suggesting a strong bias of pronunciation distribution in the open data.

\begin{tabular}{|c|c|}
\hline Scripts & Accuracy \\
\hline HIRAGANA & 89.2 \\
\hline KATAKANA & 86.6 \\
\hline
\end{tabular}

Table 3 Open test accuracy for the basic method

\section{Performance of the improved method}

Table 4 shows the average results for all 268 occurrences. The accuracy of the basic method (Table 3) was lower than that of our improved proposal in all window sizes, and it was outperformed at a window size of ten by about 3.5\% for both Hiragana and Katakana.

\begin{tabular}{|c|c|c|c|}
\hline \multicolumn{1}{|c|}{ Script } & $\mathbf{M = 2}$ & $\mathbf{M}=\mathbf{5}$ & $\mathbf{M = 1 0}$ \\
\hline HIRAGANA & 89.9 & 90.3 & $\mathbf{9 2 . 9}$ \\
\hline KATAKANA & 89.2 & 88.4 & $\mathbf{8 9 . 9}$ \\
\hline
\end{tabular}

Table 4 Open test accuracy for the improved method 


\subsection{Degree of ambiguity}

Here, we examine the relationship between the degree of pronunciation ambiguity and pronunciation accuracy using a cross-validation test for training data $^{2}$ for the improved method with Hiragana.

\section{Average case}

We conducted the first experiment with twenty words ${ }^{3}$ that were selected randomly from the Ambiguous Name List (Section 3.1). The average ambiguity was 2.1, indicating the average performance of the improved proposal.

\begin{tabular}{|l|l|l|l|l|}
\hline Class & $\mathbf{M = 2}$ & $\mathbf{M}=\mathbf{5}$ & $\mathbf{M}=\mathbf{1 0}$ & basic \\
\hline 2.1 & $\mathbf{8 9 . 2} \%$ & $\mathbf{9 0 . 9} \%$ & $\mathbf{9 2 . 3} \%$ & $67.5 \%$ \\
\hline
\end{tabular}

Table 5 Average cases

Table 5 summarizes the ten-fold cross validation, where $M$ in the table is the training data size (window size). The accuracy changes word by word, though the average was high about $90 \%$ of the time.

The "basic" column shows the average accuracy of the basic method, i.e., the percentage for the most frequent pronunciation. The improved method achieves much better accuracy than the "basic" one.

\section{The most ambiguous case}

Next, we obtained the results (Table 6) for the most ambiguous cases, where the degree of ambiguity ranged from six to eleven ${ }^{4}$. The average ambiguity was 7.1.

\begin{tabular}{|l|l|l|l|l|}
\hline Class & \multicolumn{1}{l|}{ M=2 } & M=5 & $\mathbf{M}=\mathbf{1 0}$ & basic \\
\hline 7.1 & $\mathbf{7 3 . 9} \%$ & $\mathbf{7 7 . 3} \%$ & $\mathbf{7 9 . 9} \%$ & $57.5 \%$ \\
\hline
\end{tabular}

Table 6 Most ambiguous cases

\footnotetext{
${ }^{2}$ There is some question as to whether the training data correctly catch all the pronunciations. The experiments in this subsection are independent of this problem, because our intention is to compare the performance of the average case and the most ambiguous case.

3東浜町, 三角町, 宮丸町, 川戸 ,下坂田, 蓬田, 金沢町, 白木 町, 神保町, 助谷, 新御堂, 系原, 駿河町, 百目木, 垣内田町, 杉山町, 百戸, 宝山町, 出来島, 神楽町.

4 小谷, 上原町, 上原, 小原, 西原, 上町, 大平, 葛原, 平田, 馬 場町, 新田, 土橋町, 大畑町, 上野町, 八幡町, 柚木町, 長田 町, 平原.
}

As we expected, the performances were poorer than the average cases outlined above, although they were still high, i.e., the average ranged from about $70 \%$ to about $80 \%$. Again, the improved method achieved much better accuracy than the "basic" method. ${ }^{5}$

\section{Discussion on Transliteration}

Transliteration (Knight and Graehl, 1998) is a mapping from one system of writing into another, automation of which has been actively studied between English and other languages such as Arabic, Chinese, Korean, Thai, and Japanese. If there are multiple translation candidates, by incorporating context in a way similar to our proposal, one will be able to disambiguate them.

\section{Conclusion}

This paper proposed a new method for reading proper names. In our proposed method, using Web pages containing Kanji and Hiragana (or Katakana) representations of the same proper names, we can learn how to read proper names with multiple readings via a state-of-the-art machine learner. Thus, the proposed process requires no human intervention. The current accuracy was around $90 \%$ for open data.

\section{References}

K. Knight and J. Graehl. 1998 Machine transliteration. Computational Linguistics, 24(4):599-612.

H. Li and J. Takeuchi. 1997. Using Evidence that is both string and Reliable in Japanese Homograph Disambiguation, SIGNL119-9, IPSJ.

Y. Umemura and T. Shimizu. 2000. Japanese homograph disambiguation for speech synthesizers, Toyota Chuo Kenkyujo R\&D Review, 35(1):67-74.

D. Yarowsky. 1996. Homograph Disambiguation in Speech Synthesis. In J. van Santen, R. Sproat, J. Olive and J. Hirschberg (eds.), Progress in Speech Synthesis. Springer-Verlag, pp. 159-175.

\footnotetext{
${ }^{5}$ For some words, the basic accuracy is higher than the cross validation accuracy because the basic method reaches all occurrences on the Web thanks to the search engine, while our improved method limits the number of training data by $\mathrm{L}$ in Section 2.3. For example, the most frequent pronunciation of “上原” has $93.7 \%$ on the Web, whereas the distribution in the training data is different from such a sharp distribution due to the limitation of $\mathrm{L}$.
} 